\title{
CONSIDERAÇÕES SOBRE EDUCAÇÃO POPULAR E ESCOLARIZAÇÃ̃O DE ADULTOS NO PENSAMENTO E NA PRÁXIS DE PAULO FREIRE
}

\author{
SÉrgIO HADDAD ${ }^{1}$ \\ Maria Clara Di Pierro²
}

\begin{abstract}
RESUMO: Este ensaio examina a perspectiva político-pedagógica emancipatória adotada por Paulo Freire com respeito à educação de adultos, válida tanto às experiências desenvolvidas nos espaços extraescolares por ação da sociedade civil quanto às práticas formativas que têm lugar nas escolas por iniciativas governamentais. $\mathrm{O}$ artigo investiga parte da obra do autor para sublinhar as principais características da educação popular de adultos e recorre à biografia e à história da educação entre as décadas de 1950 e 1990 para evidenciar a contribuição do pensamento e da práxis de Freire no alargamento dos direitos educativos e nas políticas públicas de educação de jovens e adultos no Brasil.
\end{abstract}

Palavras-chave: Paulo Freire. Educação de jovens e adultos. Educação popular.

\section{CONSIDERATIONS ON POPULAR EDUCATION AND ADULTS SCHOOLING IN THE THOUGHT AND PRACTICE OF PAULO FREIRE}

\begin{abstract}
This essay examines the emancipatory political-pedagogical perspective adopted by Paulo Freire for adult education, valid both to experiences developed in out-of-school spaces by the action of civil society, and to the training practices that take place in schools through government initiatives. It investigates part of the author's work to underline the main characteristics of popular adult education and it also uses the biography and history of education between the 1950s and 1990s to highlight the contribution of Freire's thought and praxis in the expansion of educational rights and in public policies for the education of young people and adults in Brazil.
\end{abstract}

Keywords: Paulo Freire. Youth and adult education. Popular education.

\section{CONSIDERACIONES SOBRE EDUCACIÓN POPULAR Y ESCOLARIZACIÓN DE ADULTOS EN EL PENSAMIENTO Y LA PRÁXIS DE PAULO FREIRE}

RESUMEN: Este ensayo examina la perspectiva político-pedagógica emancipadora adoptada por Paulo Freire con respecto a la educación de adultos, válida tanto a las experiencias desarrolladas en los espacios extraescolares por la acción de la

1.Ação Educativa - São Paulo (SP), Brasil. E-mail: sergiohaddad@terra.com.br

2.Universidade de São Paulo - Faculdade de Educação - São Paulo (SP), Brasil. E-mail: mcpierro@usp.br

Editora de Seção: Ivany Pino 
sociedad civil como a las prácticas formativas que se desarrollan en las escuelas por iniciativas gubernamentales. El artículo investiga parte del trabajo del autor para resaltar las principales características de la educación popular de adultos y se basa en su biografía y en la historia de la educación entre los años 1950 y 1990 para destacar la contribución del pensamiento y de la praxis de Freire a la ampliación de los derechos educativos y a las políticas públicas de educación de jóvenes y adultos en Brasil.

Palabras-clave: Paulo Freire. Educación para jóvenes y adultos. Educación popular.

\section{Introdução}

o longo de várias décadas dedicadas à educação escolar e extraescolar, à formação de educadores
eà pesquisa sobre educação de jovens e adultos, com frequência fomos inquiridos (quase sempre
por interlocutores céticos) sobre a viabilidade de uma pedagogia popular emancipatória - nos termos propostos por Paulo Freire - no âmbito da educação escolar e, em especial, no ensino público. O próprio Freire respondeu a essa indagação diversas vezes, como no ensaio "Escola pública e educação popular" (FREIRE, 1992a).

Neste artigo, tecemos considerações sobre essa temática, ancoradas na vida e na obra do educador brasileiro e na história da educação de jovens e adultos no Brasil (na qual Freire imprimiu marcas indeléveis), somando argumentos em favor da tese de que uma pedagogia emancipatória na educação escolar de jovens e adultos não só é possível mas também, sobretudo, necessária, como o próprio autor postulou e colocou em prática durante a vida.

Uma das ocasiões em que abordou o tema, na coletânea de ensaios Política e Educação, em artigo intitulado "Educação de Adultos hoje", Paulo Freire afirmou que "a Educação de Adultos é melhor percebida quando a situamos hoje como Educação Popular” (FREIRE, 1992a, p. 16). O autor defendia que a educação de adultos vinha se modificando ao longo do tempo e que a realidade impôs aos educadores e educadoras o desenvolvimento de uma nova sensibilidade a respeito do cotidiano dos setores populares. Alertava sobre a necessidade de os educadores não se ocuparem apenas com os conteúdos e a didática, mas incorporarem a reflexão crítica sobre a realidade dos seus educandos como forma de ampliar o sentido político das práticas educacionais.

A prática educativa, reconhecendo-se como prática política, se recusa a deixar-se aprisionar na estreiteza burocrática de procedimentos escolarizantes. Lidando com o processo de conhecer, a prática educativa é tão interessada em possibilitar o ensino de conteúdos às pessoas quanto em sua conscientização (FREIRE, 1992a, p. 16).

Nesse mesmo artigo, Freire chama a atenção para o fato de que os ganhos de consciência dos setores oprimidos se fariam não por uma ação vertical de educadores sobre educandos, como se fosse possível inculcar informações e posturas políticas sem uma ação cognoscente autônoma daquele que aprende. $\mathrm{O}$ ato de conhecer, como ação humana, não se realiza de fora para dentro, mas sim por meio de uma atitude de busca, de curiosidade daquele que aprende, estimulado por quem ensina. Dessa forma, é possível aos educandos a superação do senso comum na direção de uma compreensão científica e crítica da sua realidade. 
Ao tomar o senso comum como ponto de partida do processo educativo, os sentimentos e sonhos dos participantes, educadores e educadoras de adultos, estariam favorecendo a autonomia dos educandos nas aprendizagens, na compreensão de seu estar no mundo e na tomada de decisões quanto ao futuro, percebido sem determinismo, como tempo de possibilidades históricas e mudança. Na visão de Freire, esse seria o projeto de emancipação ao qual a educação de adultos, promovida por educadores progressistas, deveria servir.

\section{Primórdios de um Pensamento Engajado}

Embora a publicação das obras seminais do autor date da segunda metade dos anos 1960, grande parte do pensamento pedagógico de Paulo Freire foi constituído no período que antecedeu seu exílio, em $1964 .{ }^{1}$

Sua filosofia da educação foi sendo forjada no transcorrer das experiências de educação e cultura populares com adultos em que se engajou naquele período. Entre os vários aspectos desse pensamento original e complexo, dois referem-se mais especificamente ao campo da educação de jovens e adultos: a não neutralidade do fazer pedagógico; e o imperativo de uma educação diferenciada da educação infantil, tanto no conteúdo quanto na metodologia.

Freire sempre foi defensor crítico das escolas públicas, compreendidas por ele como um espaço de disputa política - um espaço que não era neutro, que comportava as contradições da sociedade em cada momento histórico. Diferentemente de alguns pensadores da pedagogia crítica, como Illich (1985), por exemplo - que entendia como limitada a possibilidade de a escola ser um instrumento de transformação social voltado aos setores populares -, Paulo Freire defendia que a escola poderia sim servir como instrumento para tal fim. No entanto, seria necessário superar o seu "caráter bancário" (FREIRE, 1975). É exatamente por isso que, ao lado da tarefa reprodutora que tem, indiscutivelmente, a educação, há uma outra, a de contradizer aquela. Aos progressistas é esta a tarefa que nos cabe, e não fatalistamente cruzar os braços (FREIRE, 1992b, p. 48).

Para o educador, a escolaridade da população, incluindo a de jovens e adultos, deveria ser tratada como uma questão ética e de direito humano. Em 1964, após o golpe civil-militar, respondendo a um inquérito instalado dentro da Universidade de Recife, local onde trabalhava coordenando o Serviço de Extensão Cultural (SEC), respondeu aos seus arguidores:

Há até quem diga que não adianta alfabetizarmos esses 36 milhões de brasileiros porque talvez "papagaio velho não aprende a ler". Como se estas legiões de analfabetos não constituíssem, para nós, seus irmãos letrados, uma prova de nosso desamor. De nossa incúria. De nosso fracasso. Nunca pretendemos ser os donos da alfabetização nacional. Há analfabetos demais. [...] Se tudo o que dissemos em nossa defesa pessoal e na defesa do SEC a ninguém convencer, paciência. Salvem-se, porém, os analfabetos (FREIRE, 2006, p. 181).

Além de constituir um imperativo ético, Freire defendeu que a escolaridade da população deveria ser uma responsabilidade do poder público. Em entrevista concedida em 1994, quando questionado sobre por que seu método não havia erradicado o analfabetismo no Brasil, assim se expressou:

Tu sabes que, teoricamente, o analfabetismo poderia ter sido erradicado no Brasil com ou sem Paulo Freire. O que faltou, centralmente, foi vontade política. A sociedade brasileira é profundamente autoritária e elitista. Para a classe dominante reconhecer os direitos fundamentais das classes populares não é fácil (FREIRE, 1994). 
Para Freire, não há dicotomia entre a educação popular e a educação escolar de jovens e adultos. A grande questão, do passado e do presente, seria como aproximar esses dois campos de práticas educativas, como construir uma escola pública popular.

Entre março e abril de 1957, o educador publicou três artigos no Diário de Pernambuco, os primeiros escritos por meio dos quais suas ideias e práticas começaram a se tornar públicas. ${ }^{2}$ Trabalhava no Serviço Social da Indústria (SESI) de Pernambuco, onde teve a oportunidade de desenvolver parte de suas experiência e concepção pedagógicas, trabalhando com operários e seus filhos. Em um dos artigos, abordou a experiência do Círculo de Pais e Professores que havia implantado naquelas escolas, nominando-a como um capítulo da educação de adultos e afirmando que seu objetivo era a formação e o desenvolvimento das responsabilidades social e política dos trabalhadores, por meio de metodologias participativas e decisões democráticas nas escolas. Nota-se aí que a educação de adultos não é reconhecida por ele apenas na sua dimensão escolar, mas como uma prática educativa que levava em conta a participação e a tomada de consciência dos trabalhadores sobre suas responsabilidades em relação à escolarização dos filhos.

Sobre o trabalho dos professores, argumentou que impor opiniões, não admitir discordâncias e não estimular o debate era, ao final, algo improdutivo. Considerando um de seus autores favoritos à época, o psicólogo romeno Zevedei Barbu, escreveu no artigo:

A aceitação das coisas impostas gera uma falsa adesão a elas. Debate, crítica, desacordo que são bem orientados e levam a conclusões, ganham a aprovação dos grupos e despertam a necessidade de novos encontros e novos debates. O processo de democracia começa aí. É no coração dos grupos, na dinâmica de suas discussões, que nasce, sem dúvida, a democracia, não como uma manifestação externa, mas como uma disposição mental (FREIRE, 1957).

Paulo Freire argumentava que a população nunca aprenderia suas responsabilidades social e política por meio apenas de discursos de pessoas bem-intencionadas, mas sim vivenciando-as. Dessa forma, o educador ressaltava a unidade da prática com as disposições mentais. Os professores deveriam apostar na participação da comunidade, mesmo que, no início, fossem recebidos com rejeição, porque, segundo Freire, a sociedade estava acostumada a posturas autoritárias e paternalistas. Criticou aqueles que subestimavam o outro - especialmente quando esse outro era um trabalhador -, convictos de que apenas eles podiam pensar e agir.

Naqueles primeiros escritos, em que refletia sobre sua prática no SESI, podemos notar a emergência de alguns conceitos que permaneceriam em sua obra nas décadas posteriores, ao longo da sua história: a educação de adultos compreendida como uma prática social escolar e não escolar; o imperativo ético da promoção da alfabetização e da escolarização de jovens e adultos, contrapondo-se ao caráter assistencial que lhe era atribuído à época e que ainda permanece aqui e ali nos tempos atuais; a responsabilidade do poder público pela oferta dessa escolarização, reconhecendo a dimensão do direito à educação escolar em qualquer etapa do ciclo de vida; a participação dos atores sociais como elemento fundamental para a construção da democracia em sociedades autoritárias como a nossa; e o diálogo e o respeito pelo conhecimento do outro como constitutivos dos processos de ensino e aprendizagem.

Nos anos que antecederam seu exílio, Paulo Freire tornou-se conhecido nacionalmente em função do método de alfabetização que formulou. Tal método foi aplicado em vários estados do Nordeste do país, com destaque para a experiência de Angicos, no Rio Grande do Norte, em janeiro de 1963. Ali, acabou ganhando visibilidade nacional propagandeada pelo Governador daquele estado, Aloizio Alves. O Presidente da República, João Goulart, convidado pelo Governador para participar da última aula, ficou impressionado com a experiência e acabou por convidar Paulo Freire para desenvolver e coordenar uma grande campanha nacional 
de alfabetização. Uma vez aceito o desafio, o pernambucano mudou-se para Brasília e começou a preparar a implantação do projeto nos estados, quando foi interrompido pelo golpe civil-militar de abril de 1964.

Naqueles tempos, a expressão educação popular não era utilizada por Freire. O educador empregava comunicação popular para designar o trabalho educacional que ocorria por meio do encontro de saberes, no diálogo entre educadores e educandos. Tal diálogo se realizava nos chamados círculos de cultura - onde ocorria a alfabetização de adultos - ou no Movimento de Cultura Popular, impulsionado pelo Prefeito de Recife, posteriormente Governador de Pernambuco, Miguel Arraes, que fomentou experiências formativas feitas pelos artistas, artesãos, poetas populares, intelectuais, escritores e outros agentes culturais para a população.

As características dos processos educativos propostas por Paulo Freire foram utilizadas em ações tanto escolares quanto não escolares: ações que ocorreram no âmbito da sociedade civil por meio de pastorais da Igreja Católica, de estudantes, de artistas e intelectuais, de militantes de partidos políticos e de movimentos sociais e populares, que realizavam seu trabalho educativo com a população inspirados no pensamento filosófico e educacional de Paulo Freire.

Quais seriam essas características? A intencionalidade política inerente aos processos educativos deveria traduzir-se de modo coerente na metodologia e nos valores difundidos. Em Educação como Prática para a Liberdade, publicado em 1965, um ano após Freire sair do Brasil - livro que sistematizava sua experiência realizada no país -, o autor propunha que a educação deveria ter um papel fundamental na promoção dos setores populares com vistas à sua participação nos destinos da sociedade brasileira. Pregava, no livro, que essa participação somente poderia ser realizada de maneira plena se a metodologia fosse também participativa, respeitadora dos conhecimentos dos educandos, horizontalizada. Finalmente, afirmava que processos educacionais deveriam afirmar compromissos éticos de respeito às diferentes culturas, valorizando o ser humano na sua vocação para liberdade, vida plena e responsabilidade para com os demais. Essas características de lidar com o poder e o saber, afirmando valores, vão demarcar o campo de atuação da educação de adultos, seja ela escolar ou não escolar.

Nos anos seguintes à partida de Freire para o exílio, o governo civil-militar atuou para responder às demandas por uma escolarização de adultos, confrontando as práticas freirianas e implantando o MOBRAL ${ }^{3}$ e o Ensino Supletivo ${ }^{4}$. Enquanto isso, parcelas da sociedade civil brasileira investiram na reconstrução do tecido social rompido com o golpe de 1964, bem como na organização e na mobilização da população para a luta por direitos e liberdade e contra o autoritarismo vigente. $O$ trabalho educativo não escolar que permeava tais ações da sociedade civil passou a ser chamado educação popular.

\section{O Sentido Político das Reformas Educacionais nos Governos Militares ${ }^{5}$}

Os governos que ocuparam o Estado no período 1964-1985 alteraram a estrutura e o funcionamento dos sistemas de ensino de $1^{\circ}$ e $2^{\circ}$ graus e de Ensino Superior. A educação escolar serviu como mediadora na relação entre o Estado, com suas características autoritárias, e a sociedade brasileira. Apesar das realçadas características de um Estado a serviço das elites, as reformas produzidas pelos governos militares acabaram por atender a alguns interesses dos setores médios e da base da estrutura social, contribuindo, em certos aspectos, com a expansão de oportunidades educacionais iniciada na década de 1930 e com seu reconhecimento como direitos de cidadania.

Foi assim com a reforma universitária, ao incorporar parcialmente algumas das propostas do meio acadêmico e do movimento estudantil - como o término da cátedra, a departamentalização, a indissociabilidade 
do ensino e da pesquisa, entre outras. Foi assim com a reforma do ensino de $1^{\circ}$ e $2^{\circ}$ graus, ao ampliar de quatro para oito anos o ensino obrigatório e romper com a dualidade da formação geral e da educação profissional. Foi assim, também, ao estabelecer o Ensino Supletivo e o Mobral para jovens e adultos das camadas populares.

O discurso doutrinário das reformas educacionais manteve parte das características liberais das legislações anteriores, agora acoplando-se ao viés de natureza tecnicista, que acabou por ganhar prioridade. De acordo com a análise de Saviani a respeito das legislações de âmbito nacional desse período:

A inspiração liberalista que caracterizava a Lei $4.024^{6}$ cede lugar a uma tendência tecnicista nas Leis $5.540^{7}$ e $5.692 .{ }^{8}$ Enquanto o liberalismo põe ênfase na qualidade ao invés da quantidade; nos fins (ideais) em detrimento dos métodos (técnicas); na autonomia versus adaptação; nas aspirações individuais ao invés das necessidades sociais; e na cultura geral em detrimento da formação profissional, com o tecnicismo ocorre o inverso. Ora, enquanto os princípios da Lei 4.024 acentuavam o primeiro elemento dos pares de conceitos acima enunciados, os princípios das Leis 5.540 e 5.692 inegavelmente fazem a balança pender para o segundo (SAVIANI, 1976, p. 198).

É importante anotar também as influências exercidas pelos organismos interamericanos, como a Aliança para o Progresso (posteriormente concretizadas pelos acordos entre Ministério da Educação - MEC - e a United States Agency for International Development - USAID), ${ }^{9}$ e pelos organismos internacionais, como a UNESCO, que vinham ganhando crescente influência nos países do Sul.

A orientação tecnicista moldava a educação às necessidades da internacionalização da economia brasileira. Nas palavras de Romanelli, "pela primeira vez, o Estado se impôs a tarefa de organizar a educação com base em sua política de desenvolvimento econômico" (1978, p. 223).

No entanto, tal intenção só se realizaria plenamente para uma pequena parte da população, na medida em que a formação dos recursos humanos de alto nível foi reservada aos extratos com maior poder econômico da sociedade, por meio dos mecanismos de seleção impostos no processo classificatório dos vestibulares, bem como das barreiras que a juventude trabalhadora enfrentava para permanecer e progredir no sistema de ensino. Os possíveis avanços democráticos da legislação acabaram sendo limitados, também, pelos escassos e mal distribuídos recursos que impediram a sua implementação para toda a população. Ainda com Saviani:

No caso do Brasil, a esperança de que as reformas operariam mudanças profundas resultou falaz. Como poderia ser de outra maneira se não houve mudanças sociais profundas? Em contrapartida, elas se revelaram eficazes para ajustar a estrutura escolar à ruptura política levada a cabo em 1964. A tendência tecnicista à luz da qual se buscou efetuar o ajustamento acima mencionado teve que proclamar as virtudes da eficiência e produtividade mas, ao mesmo tempo, não pôde se furtar às proclamações ainda que amplas do "humanismo tradicional" de orientação liberal. Esta contradição exprime a contradição objetiva vivida no seio da organização escolar (1976, p. 193).

\section{O Sentido Político da Educação de Adultos nos Governos Militares}

Em meados de 1972, a Secretaria Geral do Ministério da Educação e Cultura expediu um documento destinado à III Conferência Internacional de Educação de Adultos, convocada pela UNESCO para Tóquio, cujo título era Adult Education in Brazil (apud Haddad, 1991, p. 110). Nele, o governo brasileiro traduzia o sentido atribuído à educação de jovens e adultos com a criação do Mobral e do Ensino Supletivo. Em sua introdução, 
o documento apontava que a educação vinha se tornando fator fundamental para o desenvolvimento das nações, particularmente depois da Segunda Guerra Mundial. No caso brasileiro, afirmava que era "recente a preocupação com a educação como elemento prioritário dos projetos para o desenvolvimento" e que havia também "uma atitude nova no sentido de encará-la como rendoso investimento" (apud HADDAD, 1991, p. 110). Tais preocupações, segundo o documento, haviam sido afirmadas com a chegada dos militares ao poder, a partir de 1964, e se refletiam por meio dos seus planos de desenvolvimento e dos planos setoriais de educação.

Para alcançar tais objetivos, o Estado brasileiro se propôs criar e implementar um sistema de educação permanente, em que a educação de adultos situava-se "na linha de frente das operações", por ser "poderosa arma capaz de acelerar o desenvolvimento, o progresso social e a expansão ocupacional" (apud HADDAD, 1991, p. 111). Contribuiria, dessa forma, para aumentar a produtividade do sistema econômico por meio da preparação de recursos humanos. O progresso social se daria na medida em que o sistema educacional gerasse oportunidades para todas as classes sociais e garantisse, ainda que tardiamente, uma educação sistemática para os adultos.

A educação de adultos seria um instrumento de expansão de oportunidades de empregos, na medida em que preparasse os brasileiros para a vida em uma sociedade moderna, qualificando-os para enfrentar as exigências presentes e futuras do mercado de trabalho. Implícita nesse discurso estava a preocupação com a migração campo-cidade que se intensificara desde os anos 1950, trazendo para o meio urbano brasileiro parcela não escolarizada da população, cuja assimilação pelos mercados de trabalho e consumo requeria acesso aos sistemas de ensino. Estavam claramente expressas no documento supracitado, as intenções estabelecidas com a implantação do Mobral e do Ensino Supletivo de dispor o sistema educacional aos ditames do modelo de desenvolvimento.

Os governos militares reprimiram os movimentos de cultura popular do período anterior ao de 1964, uma vez que poderiam, por meio de processos educativos, ampliar o sentido de classe das manifestações populares de jovens e adultos, como propunha Paulo Freire. Um conjunto de pessoas foi preso, torturado ou obrigado a deixar o país, como ocorreu com o educador alvo deste artigo. Posteriormente, implementando o Mobral e o Ensino Supletivo, os governos de então procuraram reconstruir, por meio da educação de adultos, sua mediação com os setores populares, contrapondo-se ao Programa Nacional de Alfabetização que o governo anterior planejara levar adiante sob liderança de Freire.

Uma ampla campanha de massa voltada à alfabetização de jovens e adultos foi promovida pelo Mobral, graças ao incremento de recursos e de estrutura. O Ensino Supletivo, por outro lado, ficaria encarregado da continuidade dos estudos nos $1^{\circ}$ e $2^{\circ}$ graus. As reformas educacionais trouxeram, pela primeira vez, ao menos em nível formal, a extensão dos serviços de educação de adultos nas etapas elementar, secundária e profissional do ensino, além de incorporar o conceito de educação permanente, ao ofertar cursos de atualização profissional.

No entanto, o sentido dessa ampliação de direitos, expresso nos documentos legais, tornava-se restrito, na medida em que o Estado se limitou a difundir a metodologia de instrução personalizada em Centros de Estudos Supletivos (CES) e a certificar a conclusão de graus de ensino mediante Exames Supletivos, eximindo-se da responsabilidade pela expansão da oferta presencial gratuita. Deixava, assim, a educação de jovens e adultos ao sabor do ensino privado. Calada a sociedade, desorganizada em suas formas de reivindicações e de interação com o Estado, os dispositivos legais não puderam ser traduzidos em uma educação pública de qualidade e em quantidade suficiente para garantir o atendimento e reverter os baixos índices de escolarização da população de jovens e adultos. Carregado por um discurso de educação de massas, com utilização dos meios de comunicação e de novas tecnologias, o Ensino Supletivo, ao se propor modelo 
da educação do futuro, acabou como marginal no sistema, sem verbas, sem apoio político, em grande medida a serviço dos interesses das empresas privadas de educação.

A tendência à privatização do Ensino Supletivo ocorreu como desdobramento de uma política deliberada do Estado. O relatório do Grupo de Trabalho criado pelo então Ministro da Educação Jarbas Passarinho para definir a política do Ensino Supletivo, em 1972, em suas recomendações e conclusões, apontou que "é de conveniência que a iniciativa privada ingresse na área dos Cursos Supletivos, assumindo o Poder Público o controle dos resultados" (apud HADDAD, 1991, p. 235).

Os mecanismos de participação da iniciativa privada não se resumiram à oferta direta de cursos. O Governo Federal firmou, ao longo do período dos governos militares, diversos convênios com empresas ou fundações do setor privado das áreas editorial e de comunicação para produção e distribuição de programas relacionados ao Ensino Supletivo. Mesmo possuindo órgãos específicos para essa finalidade, como a Fundação Centro Brasileiro de Rádio e Televisão Educativas, o Ministério da Educação assinou diversos contratos com as fundações Roberto Marinho e Bradesco paraprodução e difusão de programas de educação de jovens e adultos pela tevê (os Telecursos de $1^{\circ}$ e $2^{\circ}$ graus). O setor privado foi beneficiado também pela venda de materiais didáticos, publicados pelas editoras Abril, Bloch, Rio Gráfica, IBEP, entre outras (HADDAD et al., 1989, p. 353; FREITAS; BICCAS, 2009, p. 254-257).

O Mobral, por outro lado, apesar de dispor de orçamento significativo e ter grande peso na publicidade do governo, mostrou uma sequência de desacertos, ganhando maior relevância pelo seu papel político de legitimador do regime autoritário do que pelos resultados de sua ação educacional, conforme estudos de Vanilda Paiva (1982). No entanto, embora exista razoável conformidade dos pesquisadores com o sentido geral da ação do Mobral, nos termos da análise da autora, algumas pesquisas têm evidenciado que, mesmo sob a gestão extremamente centralizada daquele órgão, desenvolveram-se em alguns territórios experiências relevantes de alfabetização de adultos e promoção da cultura popular (SILVA; FREITAS, 2014, 2019).

A educação escolar de adultos promovida pelos governos militares manteria, dessa forma, o mito da sociedade democrática brasileira, ao propor às camadas populares uma nova chance individual de ascensão social, limitada pelas desigualdades produzidas pelo modo de produção. Isso, no entanto, não se efetivaria.

\section{A Presença do Pensamento de Paulo Freire na Resistência ao Regime Militar}

O pensamento (e a prática) de Paulo Freire, combatido pelo regime militar e substituído no plano institucional pelo Mobral e pelo Ensino Supletivo, acabou se enraizando na sociedade brasileira como uma ação de dimensões política e educacional, ação essa que ficou conhecida como Movimento de Educação Popular. Tal corrente (que ganhou expressão também nos demais países da América Latina) foi nutrida e encontrou fundamentos ético-políticos e pedagógicos nas obras que Freire escreveu no exílio chileno, sobretudo Educação como Prática da Liberdade e Pedagogia do Oprimido, publicadas no Brasil, respectivamente, em 1967 e 1970.

A Educação Popular foi se enraizando na sociedade brasileira em espaços de resistência e reconstrução do tecido social; enraizou-se onde ocorreu vontade política de ensinar e aprender e nos espaços da vida dos setores populares, partindo-se da discussão e da tomada de consciência sobre seus problemas e sobre a realidade em que tais setores viviam, somando-se a isso a organização e a mobilização políticas. Era ali que se plantavam pequenas sementes de atuação contra o regime militar.

Nas palavras de Carlos Rodrigues Brandão:

[...] projeto utópico de uma Educação não tanto "para o povo", mas "com o povo" e "a partir de suas vidas, saberes e culturas" [...] locais sempre abertos a quem queira chegar e conviver com a 
aventura do partilhar o aprender e o saber. Remando na contracorrente de uma ilusória filosofia do aprender, baseada no "sucesso" individual, e no "estude para ser o melhor e conseguir para você mesmo o melhor". Locais em que chegam para aprender ou para aperfeiçoar a sua leitura de palavras e acabam aprendendo também a ler, crítica e criativamente, o seu próprio mundo e a sua própria vida (BRANDÃO, 2009, p. 12).

Foi nas Comunidades Eclesiais de Base da Igreja Católica, nos grupos de mulheres das periferias urbanas, nos movimentos contra a carestia, no novo sindicalismo, nos movimentos de trabalhadores rurais e em tantos outros espaços da vida da população que a ideia de se reunir para partilhar problemas, dialogando com diferentes saberes e culturas, viria a se constituir em ações voltadas a um projeto de transformação social emancipatória.

A literatura sociológica sobre os movimentos sociais analisou diversas dessas práticas das décadas de 1970 e 1980 (JARA; FALKEMBACH, 2013; SADER, 2001, entre outros), algumas das quais foram registradas também pelas metodologias de pesquisa-ação participativa e de sistematização difundidas pela corrente da Educação Popular (JARA, 1996; JARA; FALKEMBACH, 2013; SOUZA, 2006). Esses estudos amiúde reportam a influência do pensamento freiriano (e muitas vezes também da Teologia da Libertação) ${ }^{10}$ nas práticas formativas dos movimentos sociais que resistiram ao regime autoritário e contribuíram para seu declínio. Assim, pesquisando a história do chamado "novo sindicalismo" na região do ABC paulista, encontraremos um curso de educação de adultos mantido pelo Sindicato dos Metalúrgicos, em que a elevação de escolaridade e de qualificação profissional se articulou às estratégias de formação sindical (PARANHOS, 1999; PRIMO, 1996). Experiências similares se desenvolveram no Sindicato dos Metalúrgicos de Santos e entre as oposições sindicais dessa categoria operária em São Paulo. O exame do movimento de seringueiros acreanos em defesa da floresta, do qual Chico Mendes foi um dos líderes, levou ao Projeto Seringueiro de alfabetização de adultos, inspirado no pensamento e na metodologia freirianos (SOUZA, 2011). Ao indagar o percurso do Movimento dos Trabalhadores Rurais Sem Terra, encontraremos desde o início práticas de formação de adultos orientadas pela filosofia freiriana (DI PIERRO; HADDAD, 1994). De modo similar, se consultarmos a trajetória dos movimentos associativos de bairros em luta por moradia e serviços públicos (água, transporte, saúde, creche e educação) nas periferias de grandes cidades, como Belém, Recife, Salvador ou São Paulo, naquele período, encontraremos numerosos núcleos de alfabetização de jovens e adultos que adaptavam às condições locais a metodologia proposta por Paulo Freire (GHANEM, 1992; SPOSITO; RIBEIRO, 1989). Muitos outros exemplos poderiam aqui ser lembrados, o que corrobora a tese de que a apropriação, pelos movimentos sociais, da filosofia da educação de Freire foi um importante instrumento da resistência ao regime autoritário.

Na segunda metade dos anos 1980, já na transição democrática, alguns desses projetos de alfabetização e educação de adultos, influenciados pelo pensamento freiriano e conduzidos por movimentos e organizações comunitárias, lograram obter apoio de órgãos públicos (como a Fundação Educar, que sucedeu o Mobral) e desenvolver-se com o apoio de governos locais, como o Projeto de Educação Básica para Jovens e Adultos da Baixada Fluminense (ANDRADE, 1993) e o Projeto Teimosia, desenvolvido junto à Prefeitura Municipal do Recife (MARQUES, 2012).

Esses são exemplos de que, apesar do controle imposto pelo Estado autoritário, espaços foram sendo conquistados não só nos movimentos sociais, mas também no interior de instituições escolares públicas e privadas, para o desenvolvimento de experiências orientadas pelo pensamento da educação popular. À medida que a sociedade foi se democratizando, um número crescente de pessoas alinhadas a essa corrente de pensamento (muitas oriundas de experiências alternativas desenvolvidas no seio da sociedade civil) passou a ocupar posições em instituições públicas, transformando suas práticas educativas. Ao mesmo tempo, as experiências de educação 
popular de inspiração freiriana também contribuíram para as lutas por uma escola pública de qualidade e em quantidade para toda a população, aumentando a pressão para a democratização do ensino público.

Quando finalmente se encerrou a longa transição para a democracia, a educação básica de qualidade para todos - aí incluídos os jovens e adultos, cujos direitos educativos foram violados na infância e na adolescência - compôs o extenso rol de reivindicações por liberdades democráticas e direitos sociais que assomou a Assembleia Nacional Constituinte. A Carta promulgada em 1988 acolheu tais demandas e reconheceu o dever do Estado na oferta gratuita do Ensino Fundamental para jovens e adultos.

Contraditoriamente, corroboraram para esse resultado não apenas as práticas de educação popular com jovens e adultos promovidas pelos movimentos sociais, mas também o legado dos serviços públicos de educação de adultos - programas de alfabetização, cursos, telecursos, exames e centros de estudos supletivos -, erigidos durante o regime militar e por ele inscritos na legislação.

\section{Paulo Freire e a Política de Educação de Jovens e Adultos na Cidade de São Paulo}

Pouco após a promulgação da Constituição Federal de 1988, que reconheceu os direitos educativos dos jovens e adultos, responsabilizando os poderes públicos pela provisão de educação escolar básica a esse grupo, realizaram-se eleições municipais. Revertendo expectativas, Luiza Erundina derrotou adversários como Paulo Maluf, José Serra e João Leiva, elegendo-se a primeira Prefeita, pelo Partido dos Trabalhadores, para governar São Paulo, a maior cidade do país. Formada em Serviço Social e Mestre em Sociologia e Política, Erundina era funcionária concursada da Secretaria do Bem-Estar Social do Município desde 1971 e, conhecedora dos desafios da governança da metrópole, cercou-se de um secretariado de alto nível, com a participação de intelectuais do porte de Marilena Chauí (Cultura), Paul Singer (Planejamento), Dalmo Dallari (Negócios Jurídicos) e Paulo Freire (Educação).

Freire permaneceu à frente da Secretaria Municipal de Educação de São Paulo (SME-SP) por dois anos e meio ${ }^{11}$ e realizou uma administração que priorizou a democratização da gestão e do acesso, a construção de uma nova qualidade do ensino (com destaque para a ressignificação do currículo nos contextos socioterritoriais das escolas e sua abordagem interdisciplinar) e a política de educação de jovens e adultos. Visando impulsionar as mudanças educativas pretendidas, estimulou a democratização da gestão e promoção da autonomia escolar, a descentralização administrativa e pedagógica, a valorização profissional e a formação continuada dos educadores.

Muitos foram os processos desencadeados para reverter a deterioração das condições físicas das unidades de ensino e a desmotivação das equipes, ${ }^{12}$ dando início a mudanças para instituir uma "escola pública, popular e democrática”. Em retrospectiva, a aprovação do Estatuto do Magistério e o debate do Regimento Comum das Escolas compõem, ao lado do Movimento de Reorientação Curricular, o legado que persistiu na política educacional do município em longo prazo. No campo da educação de jovens e adultos, transformações significativas foram promovidas e ressoam até o presente, mais de três décadas depois.

A rede municipal de ensino contava então com cerca 1 milhão de estudantes, 65 mil servidores e sete centenas de unidades escolares, parte das quais ofertava, desde 1976, cursos noturnos para jovens e adultos, à época designados como Ensino Supletivo de $1^{\circ}$ grau. Como herança do extinto Mobral (1971-1985) e de sua sucedânea, a Fundação Educar (1985-1990), a prefeitura mantinha também, no âmbito da Secretaria de BemEstar Social (SEBES), um programa de alfabetização e pós-alfabetização de jovens e adultos desenvolvido em espaços comunitários, cujos educadores não tinham necessariamente habilitação para o magistério. 
Já no discurso de posse à frente da SME-SP, Freire reafirmou a necessidade do reconhecimento e do respeito à cultura popular no interior da escola pública. No documento intitulado "Construindo a Educação Pública Popular”, de fevereiro de 1989, evidenciava-se a concepção freiriana sobre educação popular:

A qualidade dessa escola deverá ser medida não apenas pela quantidade de conteúdos transmitidos e assimilados, mas igualmente pela solidariedade de classe que tiver construído, pela possibilidade que todos os usuários da escola - incluindo pais e comunidade - tiverem de utilizá-la como um espaço para a elaboração de sua cultura. Não devemos chamar o povo à escola para receber instruções, postulados, receitas, ameaças, repreensões e punições, mas para participar coletivamente da construção de um saber, que vai além do saber de pura experiência feito, que leve em conta as suas necessidades e o torne instrumento de luta, possibilitando-lhe transformar em sujeito de sua própria história. A participação popular na criação da cultura e da educação rompe com a tradição de que só a elite é competente e sabe quais as necessidades e interesses de toda a sociedade. A escola deve ser também um centro irradiador de cultura popular, à disposição da comunidade, não para consumi-la, mas para recriá-la. A escola é também um espaço de organização política das classes populares. A escola como um espaço de ensino-aprendizagem será então um centro de debates de ideias, soluções, reflexões, onde a organização popular vai sistematizando sua própria experiência (SÃO PAULO, 1989, p. 7).

Na mensagem dirigida aos educadores e educadoras, logo no início da gestão, Freire escreveu:

O aluno trabalhador não pode ser tratado como um aluno de segunda categoria. A educação de jovens e adultos não será tratada como caso de assistência social. O Ensino Noturno terá sério tratamento, assim como o Ensino Supletivo, a ser visto na sua relação com o Ensino Regular. Reforçaremos o caráter sistemático da educação de adultos, contra o caráter emergencial das campanhas (FREIRE, 2020, p. 64).

Para perseguir essas diretrizes, diversas estratégias foram simultaneamente acionadas pela SME-SP, todas respeitando a orientação freiriana de gestão participativa. Já no início de 1989, foi organizado o Simpósio São Paulo 1989: Educar Adultos Para Quê?, no qual ações e prioridades foram sendo desenhadas em diálogo com diferentes atores. No ano seguinte, o Seminário Repensando a Escola para o Jovem e o Adulto Trabalhador refletiu sobre o diagnóstico e as demandas formuladas pelos agentes, amadurecendo as diretrizes da Reorientação Curricular do Ensino Noturno.

Respondendo às demandas de organizações sociais e movimentos populares que desenvolviam atividades de alfabetização de jovens e adultos e também com o intuito de incentivar a participação social na administração municipal, foram estabelecidas parcerias que deram origem ao Movimento de Alfabetização de Adultos (MOVA). As organizações sociais eram responsáveis por identificar espaços comunitários e mobilizar educandos e alfabetizadores, aos quais a secretaria proporcionava formação contínua e supervisão, além de prover recursos financeiros e materiais. Segundo Pontual, "ao final de 1992 estes convênios abrangiam 73 entidades populares, que haviam constituído cerca de 1.000 núcleos (classes) e atendiam cerca de 20.000 jovens e adultos" (1997, p. 24).

O MOVA serviu de modelo para programas similares, desenvolvidos em outras municipalidades do país, e constituiu um Fórum Municipal autônomo, capaz de incidir na política municipal de educação, que assegurou a permanência do programa nos governos subsequentes, malgrado a descontinuidade políticoadministrativa que marcou as alternâncias de partidos no poder. Em 2005, o MOVA foi institucionalizado 
na Lei Municipal n. 14.058 e desde então a parceria entre organizações sociais e a prefeitura para cursos de alfabetização de jovens e adultos constitui política perene da municipalidade.

Cumprindo o compromisso de desvencilhar a educação de adultos do ranço assistencialista em que estivera imersa, Freire propôs que o programa de alfabetização e pós-alfabetização, até então alocado na SEBES, fosse transferido à SME e constituiu um Grupo de Trabalho para tratar dessa transição. A questão mais delicada dessa passagem foi a realocação dos 950 monitores e a qualificação profissional de parte deles, pois 283 não possuíam formação pedagógica para ingressar no quadro do magistério municipal, uma vez que, até então, exigia-se deles apenas a conclusão do ensino secundário. A gestão de Freire optou por valorizar a experiência acumulada por esses educadores, estabelecendo uma transição durante a qual foi oferecido, em nove núcleos distribuídos na cidade, um curso especial de formação em serviço ao magistério, ${ }^{13}$ especialmente desenhado para esse grupo e realizado em horários compatíveis com o trabalho docente.

Foi também constituída a chamada Frente do Funcionalismo, voltada à elevação de escolaridade de trabalhadores da administração municipal, em especial daqueles das áreas operacionais de zeladoria das subprefeituras - entre os quais o analfabetismo e a baixa escolaridade eram frequentes -, mas também dos funcionários de demais órgãos que necessitavam elevar a escolaridade para atender aos requisitos dos concursos públicos exigidos pela nova Lei Orgânica do Município. Essa frente atuou também junto à Secretaria da Saúde, em que 46\% dos quatro mil atendentes de enfermagem não haviam concluído o $1^{\circ}$ grau, para os quais foi especialmente formulado e implementado o Projeto Supletivo, com aulas em horários compatíveis com o trabalho, realizadas em quatro núcleos distribuídos pela cidade, cujas vagas excedentes foram abertas aos interessados das comunidades (SÃO PAULO, 1991).

Convicto da necessidade de conceder voz aos alfabetizandos, Paulo Freire estimulou a realização, em dezembro de 1990, do Congresso de Alfabetizandos, que coletou testemunhos e reuniu mais de cinco mil alfabetizandos e educadores do MOVA e dos demais programas de educação de adultos da municipalidade.

As especificidades dos cursos para jovens e adultos ministrados em horário noturno nas escolas municipais foram consideradas na formação continuada de educadores e educadoras, bem como no Movimento de Reorientação Curricular. As mudanças curriculares foram incentivadas, mas prevaleceu a regra da livre adesão e as escolas tiveram sua autonomia respeitada. Os educadores receberam apoio para desenvolverem projetos interdisciplinares inovadores que enraizassem o currículo no território e na cultura da comunidade escolar.

Documentos da época asseveram que, entre 1989 e 1992, as matrículas no período noturno na rede municipal paulistana cresceram $57 \%$ e que, ao final do quadriênio, apenas $6 \%$ das unidades escolares permaneciam fechadas nesse turno, em contraste com a situação anterior, em que $58 \%$ das escolas municipais permaneciam fechadas à noite ${ }^{14}$.

Embora de modo discreto, Freire não se eximiu naquele período de incidir também nas políticas públicas de âmbito nacional, às quais cabia concretizar os direitos educativos dos adultos reconhecidos pela nova Constituição. Estimulado pela UNESCO, que havia declarado 1990 o Ano Internacional da Alfabetização, o MEC constituiu, ao final do governo de José Sarney (1985-1989), uma Comissão Nacional formada por dirigentes das três esferas de governo, professores universitários e representantes de organizações da sociedade civil para planejar a celebração. Freire compôs a Comissão Nacional do Ano Internacional da Alfabetização (CNAIA) como um dos representantes dos municípios e foi designado seu presidente, cargo ao qual renunciou após as eleições de 1989, alegando incompatibilidade política com o governo de Fernando Collor de Mello, recém-eleito para o Executivo federal. ${ }^{15}$ 


\section{Considerações Finais}

Ao longo desse ensaio, procuramos evidenciar que muitas das experiências de educação de adultos desenvolvidas à luz dos preceitos da educação popular materializaram a crença de Freire na escola como um espaço passível de promoção da mudança social, ao lado das práticas formativas desenvolvidas no interior dos movimentos populares. Mesmo reconhecendo a dificuldade de um trabalho crítico dentro da escola, o autor confiou nessa possibilidade, ao apontar, em suas experiências, mecanismos de resistência e afirmação.

A valorização da escola como espaço de educação popular pode ser acompanhada por meio da obra e da prática do educador: no Brasil, Paulo Freire assessorou trabalhos de alfabetização de governos de diversas posições políticas, assumiu o Programa Nacional de Alfabetização em 1963; no exílio, colaborou com o governo chileno, trabalhou na Universidade de Harvard, nos EUA, e, a partir de Genebra, local onde morou por dez anos a convite do Conselho Mundial de Igrejas, assessorou os novos governos de países africanos que haviam se libertado do jugo da metrópole portuguesa a partir de 1975, em processos educativos decoloniais. Poucos anos após seu retorno ao Brasil, assumiu, em 1989, a Secretaria Municipal de Educação da cidade de São Paulo, no governo da Prefeita Luiza Erundina. Quase todas essas atividades se deram no âmbito do setor público e diversas delas estavam relacionadas à escolarização de pessoas jovens e adultas.

Na perspectiva de "nadar contra a maré" por uma educação popular na escola, Paulo Freire estimulou educadores e educadoras de adultos a não separar o ensino dos conteúdos do desvelamento da realidade, assim como a incentivar a organização das classes populares na luta em favor da transformação democrática da escola e da sociedade, no sentido da superação das injustiças sociais. Para ele, a educação popular no âmbito das instituições escolares:

É a que respeita os educandos, não importa qual seja sua posição de classe e, por isso mesmo, leva em consideração, seriamente, o seu saber de experiência feito, a partir do qual trabalha o conhecimento com rigor de aproximação aos objetos. É a que trabalha, incansavelmente, a boa qualidade do ensino, a que se esforça em intensificar os índices de aprovação através de rigoroso trabalho docente e não com frouxidão assistencialista, é a que capacita suas professoras cientificamente à luz dos recentes achados em torno da aquisição da linguagem, do ensino da escrita e da leitura. Formação científica e clareza política de que as educadoras e os educadores precisam para superar desvios que, se não são experimentados pela maioria, se acham presentes em minoria significativa (FREIRE, 1992b, p. 49).

Paulo Freire alerta para a importância de a escola ser também um espaço a serviço da mudança social, como é a educação popular. O papel político do educador e da educadora é fundamental nesse desafio, assim como o seu engajamento no sindicato e no partido político, sem que esses espaços se confundam:

[...] é que os conflitos sociais, o jogo de interesses, as contradições que se dão no corpo da sociedade se refletem necessariamente no espaço das escolas. E não podia deixar de ser assim. As escolas e a prática educativa que nelas se dá não poderiam estar imunes ao que se passa nas ruas do mundo (FREIRE, 1992b, p. 49).

\section{Contribuição dos Autores}

Metodologia, Haddad S e Di Pierro MC; Problematização e Conceituação, Haddad S e Di Pierro MC; Análises e Redação, Haddad S e Di Pierro MC. 


\section{Notas}

1. Em entrevista concedida a um órgão da imprensa escrita em 1994, Freire afirmou: "A tese acadêmica que escrevi em 1959, 'Educação e Atualidade Brasileira’, já era um anúncio da Pedagogia do Oprimido, de 1968. Era o núcleo central de todo esse pensamento que eu desenvolvi também no livro Educação como Prática da Liberdade" (FREIRE, 1994).

2. Os artigos publicados no Diário de Pernambuco em 1957 chamavam-se: "Círculo de Pais e Professores - um capítulo da educação de adultos" (31 de março); "Ainda a propósito de Círculo de Pais e Professores" (7 de abril); e "Ainda os Círculos de Pais e Professores: sua preparação e sua realização” (21 de abril).

3. O Movimento Brasileiro de Alfabetização foi instituído pelo decreto n. 62.455, de 22 de março de 1968.

4. Estabelecido pela Lei n. 5.692, de 1971.

5. Este subtítulo e o seguinte, assim como seus conteúdos, são similares aos itens C e D do capítulo II da tese de doutorado de Sérgio Haddad, um dos autores deste artigo, tese não publicada e que consta das referências.

6. De 20 de dezembro de 1961. Fixou as diretrizes e bases da educação nacional.

7. De 28 de novembro de 1968. Fixou normas de organização e funcionamento do Ensino Superior e sua articulação com a escola média.

8. De 11 de agosto de 1971. Fixou diretrizes para o ensino de $1^{\circ}$ e $2^{\circ}$ graus.

9. Lei n. 5.540, de 1968, que fixou normas de organização e funcionamento do Ensino Superior e sua articulação com a escola média.

10. A Teologia da Libertação foi uma corrente que se difundiu a partir da explicitação pela Igreja Católica da opção preferencial pelos pobres nas Conferências Episcopais Latino-americanas de Medellín (1968) e Puebla (1979). Para uma análise histórica e dos fundamentos dessa corrente, consultar Zanini, Bacega e Zappia (2011).

11. Freire deixou a secretaria para retomar a atividade intelectual e por considerar que o alicerce de seu projeto fora edificado, de modo que sua equipe pudesse dar continuidade. Foi sucedido pelo Chefe de Gabinete, o também professor da Pontifícia Universidade Católica, Mario Sérgio Cortella.

12. A gestão do Prefeito Jânio Quadros, que antecedeu à de Luiza Erundina, recolheu arbitrariamente documentos curriculares elaborados com a participação dos educadores e afrontou uma greve de servidores da educação com desconto de salários, processos administrativos e demissões em massa.

13. Com carga horária total de 1.760 horas, o curso se desenvolvia por 10 horas/aula semanais, parte das quais realizadas aos sábados, e também por atividades coletivas e registros de práticas, sendo a conclusão do curso precedida de apresentação de monografia. Coordenado pela Professora Cecília Guaraná, o curso especial foi autorizado pelo Conselho Municipal de Educação e vinculado administrativamente à EMPSG Derville Allegretti, uma das poucas escolas municipais de Ensino Médio em que a SME mantinha turmas de habilitação regular ao magistério (SÃO PAULO, 1992a).

14. Reunidos para celebrar os trinta anos da gestão de Paulo Freire à frente da SMESP, um coletivo de educadores ex-servidores da instituição criou um repositório de documentos que podem ser consultados em: https://sites. google.com/unesp.br/coletivopaulofreire/acervo-secretaria-municipal-de-s\%C3\%A3o-paulo-1989-1992. 
15. Paulo Freire foi substituído na presidência da CNAIA pelo outro representante dos municípios, José Eustáquio Romão, então Secretário de Educação de Juiz de Fora (MG), que levou adiante a produção do documento "Alfabetizar e Libertar", propondo um processo participativo de mobilização em prol da alfabetização, mal-recebido pelo Ministro da ocasião e jamais publicado pelo MEC (DI PIERRO, 2000, p. 66).

\section{Referências}

ANDRADE, E. R. Nos limites do possível: uma experiência político-pedagógica na Baixada Fluminense. 1993. Dissertação (Mestrado em Educação) - Instituto de Estudos Avançados em Educação, Fundação Getúlio Vargas, Rio de Janeiro, 1993.

ARELARO, L. R. G. A competência gestora de um grande educador. In: FREIRE, P. Direitos humanos e educação libertadora: gestão democrática da educação pública na cidade de São Paulo. 2. ed. Rio de Janeiro/ São Paulo: Paz e Terra, 2020. p. 307-324.

BEISIEGEL, C. Paulo Freire. Recife: Fundação Joaquim Nabuco/Editora Massangana, 2010. (Coleção Educadores.)

BRANDÃO, C. R. Aprender a saber com e entre outros. In: ASSUNÇÃO, R. (org.). Educação popular na perspectiva freiriana. São Paulo: Instituto Paulo Freire, 2009. p. 9-18.

DI PIERRO, M. C. As políticas públicas de educação básica de jovens e adultos no Brasil do período 1985/1999. 2000. 314 f. Tese (Doutorado em História e Filosofia da Educação) - Programa de Pós-graduação em Educação, Pontifícia Universidade Católica de São Paulo, São Paulo, 2000.

DI PIERRO, M. C.; HADDAD, S. A educação no Movimento dos Trabalhadores Rurais Sem Terra em Bagé e Sarandi (RS). Brasília: INEP, 1994. (Inovações educacionais, 2.)

FÓRUM DE POLÍTICAS MUNICIPAIS DE EDUCAÇÃO DE JOVENS E ADULTOS. Educação de jovens e adultos: Subsídios para elaboração de políticas municipais. São Paulo: CEDI, 1990. (Série Documentos, 5.)

FRANCO, D. S. A gestão de Paulo Freire à frente da Secretaria Municipal de Educação de São Paulo (1989 1991) e suas consequências. Pro-Posições, Campinas, v. 25, n. 3 (75), p. 103-121, set./dez. 2014. https://doi. org/10.1590/0103-7307201407506

FREIRE, A. M. A. Paulo Freire, uma história de vida. Indaiatuba: Villa das Letras, 2006.

FREIRE, P. Círculo de pais e professores: capítulo da educação de adultos. Diário dePernambuco, Recife, 31 mar. 1957, p. 3.

FREIRE, P. Conscientização e alfabetização, uma nova visão do processo Estudos Universitários - Revista de Cultura da Universidade de Recife, Recife, n. 4, abr./jun., 1963.

FREIRE, P. Educação como prática da liberdade. Rio de Janeiro: Paz e Terra, 1967.

FREIRE, P. Pedagogia do oprimido. 2. ed. Rio de Janeiro: Paz e Terra, 1975.

FREIRE, P. Escola pública e educação popular. Política e educação: ensaios. São Paulo: Cortez, 1992a. p. 47-52. (Questões de Nossa Época, 23.) 
FREIRE, P. Educação de adultos hoje: algumas reflexões. Política e educação: ensaios. São Paulo: Cortez, 1992b. p. 16-17. (Questões de Nossa Época, 23.)

FREIRE, P. Educação pela fome. Entrevista concedida à Marilene Felinto e Mônica R. da Costa. Folha de S. Paulo, São Paulo, 29 maio 1994. Disponível em: https://www1.folha.uol.com.br/fsp/especial/mais/ historia/290594.htm. Acesso em: 11 ago. 2021.

FREIRE, P. Direitos humanos e educação libertadora: gestão democrática da educação pública na cidade de São Paulo. 2. ed. Rio de Janeiro/São Paulo: Paz e Terra, 2020.

FREIRE, P. R. N. Educação e atualidade brasileira. 1959. Tese (Concurso para a cadeira de História e Filosofia da Educação) - Escola de Belas Artes de Pernambuco, Recife, 1959.

FREITAS, M. C.; BICCAS, M. S. História social da educação no Brasil: 1926-1996. São Paulo: Cortez, 2009.

GHANEM JR., E. G. Lutas populares, gestão e qualidade da escola pública. 1992. Dissertação (Mestrado em Educação) - Faculdade de Educação, Universidade de São Paulo, São Paulo, 1992.

HADDAD, S. Estado e educação de adultos (1964/85). 1991. Tese (Doutorado em Educação) - Faculdade de Educação, Universidade de São Paulo, São Paulo, 1991. Disponível em: http://forumeja.org.br/sites/forumeja. org.br/files/estado-e-educacao-de-adultos-1964-1985-()-sergio-haddad.pdf. Acesso em: 30 jun. 2021.

HADDAD, S. et al. O ensino supletivo - função suplência - no Brasil: indicações de uma pesquisa. Revista Pedagógica de Estudos Pedagógicos, Brasília, v. 70, n. 166, p. 346-370, set./dez. 1989.

ILLICH, I. Sociedade sem escolas. 7. ed. Petrópolis: Vozes, 1985.

JARA, O. Para sistematizar experiências. João Pessoa: Ed. Universitária UFPB, 1996.

JARA, O.; FALKEMBACH, E. M. F. Educação popular e sistematização de experiências. In: STRECK, D. R.; ESTEBAN, M. T. (orgs.). Educação popular: lugar de construção social coletiva. Petrópolis: Vozes, 2013. p. 151-166.

MARQUES, E. S. V. O discurso curricular do Projeto Teimosia e suas interlocuções com a educação popular. In: REUNIÃO ANUAL DA ANPED, 35., 2012, Ipojuca, Educação, cultura, pesquisa e projetos de desenvolvimento: O Brasil do século XXI. Rio de Janeiro: Anped, 2012.

PAIVA, V. Mobral: um desacerto autoritário I, II, III. Revista Síntese, Rio de Janeiro, v. 9, n. 23, 24, 25, 1982.

PARANHOS, K. R. Educação sindical em São Bernardo nos anos setenta e oitenta. Revista de Sociologia e Política, Curitiba, n. 13, p. 153-174, nov. 1999.

PONTUAL, P. C. Desafios pedagógicos na construção de uma parceria: a experiência do MOVA-São Paulo (1989-1993). Alfabetização e Cidadania, São Paulo, n. 5, p. 23-32, jul. 1997.

PRIMO, A. A. O Centro Educacional Tiradentes. Escola do Sindicato dos Metalúrgicos de São Bernardo do Campo e Diadema (1974-1979). 1996. 138 f. Dissertação (Mestrado em História Social) - Faculdade de Filosofia, Ciências e Letras, Universidade de São Paulo, São Paulo, 1996.

ROMANELLI, O. O. História da Educação no Brasil 1930/1973. Petrópolis: Editora Vozes Ltda., 1978.

ROSSIAUD, J.; SCHERER-WARREN, I. A democratização inacabável: as memórias do futuro. Petrópolis: Vozes, 2000. 
SADER, E. Quando novos personagens entraram em cena: experiências, falas e lutas dos trabalhadores da Grande São Paulo, 1970-80. 4. ed. Rio de Janeiro: Paz e Terra, 2001.

SÃO PAULO (Cidade). Secretaria Municipal de Educação de São Paulo. Aos que fazem a educação conosco em São Paulo. Construindo a Educação Pública Popular. Suplemento do Diário Oficial do Município, 01 fev. 1989.

SÃO PAULO (Cidade). Prefeitura Municipal. Secretaria Municipal de Educação. Secretaria Municipal de Saúde. Frente do funcionalismo: projeto Supletivo Educação e Saúde. São Paulo: SME-DOT, 1991. (Caderno 1). Disponível em: https://sites.google.com/unesp.br/coletivopaulofreire. Acesso em: 30 jun. 2021.

SÃO PAULO (Cidade). Prefeitura Municipal. Secretaria Municipal de Educação. Formação especial para o magistério: uma experiência pedagógica na Rede Municipal de Ensino (1989-1992). São Paulo: SME-DOT, 1992a. Disponível em: https://sites.google.com/unesp.br/coletivopaulofreire. Acesso em: 30 jun. 2021.

SÃO PAULO (Cidade). Prefeitura Municipal. Secretaria Municipal de Educação. Reorientação curricular do ensino noturno: construindo um novo ensino noturno. Sistematização dos projetos elaborados pelas escolas. São Paulo: SME-DOT, 1992b. (Construindo a Educação do Jovem e Adulto Trabalhador, Caderno 3). Disponível em: https://sites.google.com/unesp.br/coletivopaulofreire. Acesso em: 30 jun. 2021.

SANTOS, M. A. P. Movimento de alfabetização de jovens e adultos. In: STRECK, D. R. et al. (orgs.). Dicionário Paulo Freire. Belo Horizonte: Autêntica, 2008. p. 274-276.

SAVIANI, D. Análise crítica da educação escolar brasileira através das leis 5540/68 e 5962/71. In: GARCIA, W. E. (org.). Educação brasileira contemporânea: organização e funcionamento. São Paulo: MacGraw-Hill do Brasil, 1976.

SAVIANI, D. Política e educação no Brasil. São Paulo: Cortez, 1987.

SILVA, J. C.; FREITAS, M. L. Q. O Mobral e as vozes dos sujeitos sertanejos, após quatro décadas. Teias, Rio de Janeiro, v. 15, n. 35, p. 132-147, 2014.

SILVA, J.C.; FREITAS, M.L. Q. Das fontes orais às fontes visuais: narrativas das ações do Mobral cultural no sertão de Alagoas (1973-1985). Educação, Santa Maria, v. 44, p. 1-26, 2019. https://doi.org/10.5902/1984644437025 SOUZA, J. D. Entre lutas, porongas e letras: a escola vai ao seringal - (re)colocações do Projeto Seringueiro (Xapuri/Acre - 1981/1990). Belo Horizonte: UFMG/FAE, 2011.

SOUZA, J. F. (org.). Investigación acción participativa: ¿qué? Desafíos a la construcción colectiva del conocimiento. Recife: Edições Bagaço, 2006.

SPOSITO, M. P.; RIBEIRO, V. M. Escolas comunitárias: contribuição para o debate de novas políticas educacionais. São Paulo: CEDI, 1989. (Cadernos do CEDI, 4.)

TELLES, S. A. S. Todo ser humano tem condição de construir conhecimento: uma experiência de formação de professor em parceria entre movimentos populares e governo municipal de São Paulo - O Projeto MOVA/ SP, 1989 - 1992. 1998. Dissertação (Mestrado em Educação) - Centro de Estudos Sociais Aplicadoos, Universidade Federal Fluminense, Niterói, 1998.

ZANINI, C. F; BACEGA, M.; ZAPPIA, R. B. A Teologia da Libertação e a opção preferencial pelos pobres na América Latina. Revista História \& Perspectivas, Uberlândia, v. 24, n. 44, p. 61-104, 15 jul. 2011. 


\section{Sobre os Autores}

SÉrgio Haddad é formado em Economia pela Universidade de São Paulo (USP), com doutorado em Educação pela mesma instituição. É pesquisador da Ação Educativa, desenvolve pesquisas nos campos da educação de jovens e adultos, da educação popular e das políticas públicas. É pesquisador sênior do CNPq.

Maria Clara Di Pierro é formada em Geografia pela Universidade de São Paulo (USP), com doutorado em Educação pela Pontifícia Universidade Católica de São Paulo (PUC-SP). É professora do Departamento de Economia da Educação e Administração Escolar da Faculdade de Educação da USP. Desenvolve pesquisas nos campos das políticas públicas de educação e da educação com pessoas jovens e adultas.

Recebido: 30 ago. 2021

Aceito: 09 set. 2021 